\title{
Synthesis of Spoken Messages from Semantic Representations
}

\section{(Semantic-Representation-to-Speech System)}

\author{
Laurence DANLOS, ErIC LAPORTE \\ Laboratotre d'Automatique Documentaire et Linguistique \\ Universite Paris 7 \\ 2 , place Jussleu \\ 75251 PARIS CEDEX 05
}

\author{
Françoise EMERARD \\ Centre National d'Etudes des Télécommunications \\ 22301 LANNION CEDEX
}

\section{Knowledge needed in a tent-to-speech system}

\subsection{Spelling-to-sound canversion}

The first problem encountered in synthesizing speech from written text is that of spelling-to-sound conversion. Certain languages are much easier than others in this respect. For example, about 50 rules are sufficient for the conversion of written spanish into phonetic symbols, with a virtually zero error rate (Santos \& Nombela 1982). For other languages, such as French or English, the problem is much greater. A phoneme does not generally correspond to only one grapheme, and the reverse is also true. For instance, the word oiseau is pronounced / wazo/ : none of its graphemes is pronounced as would be expected (i.e. /o/ for $0, / i /$ for $i, / s /$ for $s$, schwa for $e, / a /$ for a and $/ y /$ for (1).

Spelling-to-sound conversion is further compltcated by the existence of non-homophonic homographs, i.e. words spelled the same but pronounced differently. The distinction between two homographs requires to know their grammatical categorles (record is pronounced ['reko:d] if it is a noun and [ri'ko:d] if it is a verb), their inflexional features (read is pronounced [ri:d] in the inf initive form and [red] in the preterite), or their semantic features (lead is pronounced [led] when it is a noun or a verb related to the metal and [1i:d] otherwise)!

In French, words in context raise the additional problem of lialson. A llaison occurs between a word ending in a mute consonant and a word beginning with a vowel. For example, the $n$ in mon is pronounced in mon arrivese but mute in mon depart. However, a llatson is made only if this phonological condition is accompanled with syntactic conditions. For example, a llaison is made between a determiner and a noun as in mon arrivese (my arrival), but not between a subject and a verb as in le limonarrive (The sllt is coming).
1. In French, semantic features are needed to distinguish only a few non-homophonic homographs, mostly technical words. 
To sum up, the phonetic conversion of French texts relles on syntactic knowledge to deal with homographs and lialsons.

\subsection{Prosody}

A text-to-speech system supposes the storage of minimum acoustic units that allow the reconstruction of the acoustic signal for any sentence. One solution consists in the choice of diphones as acoustic units. A diphone is defined as a segment (about 1,200 for French) that goes from the steady state of a phonetic segment to the steady state of the following segment and that contains in its heart all the transitional part between two consecutive sounds.

Furthermore, the issue of increasing the natural-ness of synthetic speech requires to take into account prosodic factors, namely, stress, timing (structuring of the utterance by pauses) and intonation. intonation is characterized by the interaction of three parameters: evolution of intensity and laryngeal frequency as functions of duration.

The prosodic behavior of one speaker was therefore subjected to a systematic study. An acceptable model was extracted from this behaviour. The prosodic processing (Emerard 1977) is based on the allocation of prosodic markers (e.g. $[=],[\#]$ ) at different points in a sentence. Fifteen prosodic markers were considered to be sufficient for determining suitable prosodic contours for the synthesis of French. Each marker assigns a melody and a rhythm to each syllable of the preceding word. More precisely, each marker may

- cause an interruption in the diphone concatenation,

- introduce a pause,

- affect to varying degrees the amplitude of laryngeal frequency $\left(F_{0}\right)$ on the last vowel of the word,

- determine rising or falling $F_{0}$ movements.

The cholce of a marker after a constituent is determined both by the syntactic category of the constituent (verbal syntagm, subordinate clause) and by its location inside the sentence, especially by the existence of a more or less complex right context. In the simple enunciative sentence Jean part (John is leaving), the prosodic processing has to give the following results: Jean [*] part [.]. Nevertheless, it is not possible to conclude with the following prosodic rules:

[*] is the marker assigned to lend of subject noun phrase]

[.] is the marker assigned to [end of verbal syntagm] because in the enunclative sentence Jean part et Marit vient (John is going away and Mary is coming), the prosodic processing has to propose: Jean [ $[=]$ part $[$,$] et$ Marie [*] vient [.]. A comparison of these two sentences clearly shows that it is not possible to assign a specific marker after a constituent only on the basis of its syntactic category. It is necessary to take its right context into account. Moreover, placing prosodic markers must be carried out in a hierarchical manner. For example, the marker between the preverbal phrase and the verbal syntagm depends on the marker assigned at the end of the clause containing them; this last marker depends in turn on the marker assigned at the end of the sentence containing the clause.

To sum up, the issue of prosody is handled by placing appropriate markers in appropriate locations. This can only be done when precise syntactic information is avallable.

\section{Production of o phanetic chain with prosodic markers}

The system which translates a semantic representation into a phonetic chain with prosodic markers has been bullt from a written text generation system (Danlos 1986) that has been modifled and completed. Let us start with a brief description of this generator.

\subsection{The generator}

The generator is modularized into a strategic component and a syntactic component. From a semantic representation such as

$$
\begin{aligned}
\text { (1) EVENT: ACT }=: \text { GIVE-PRESENT } \\
\text { ACTOR }=\text { HUM } 1=: \text { HUMAN } \\
\text { NAME }=\text { Jean } \\
\text { OBJECT }=\text { TOK } 1=: \text { FLOWER } \\
\text { TYPE }=\text { anémone } \\
\text { DATIVE }=\text { HUM2 }=: \text { HUMAN } \\
\text { NAME = Marie } \\
\text { GOAL }=: \text { HAPPY } \\
\text { OBJECT }=\text { HUM2 }
\end{aligned}
$$

the strategic component makes conceptual dectsions (e.g. the decision about the order of the informations) and linguistic decisions (e.g. the decision about the number of sentences) (Danlos $1984 \mathrm{a}$ and b). The output of this component is a "text template" (TT) that ind1cates

1) the splitting up of the text into sentences:

$T T=$ (Sentence 1 . Sentence 2 .) 
2) for each sentence, its structure in terms of main clause and subordinate clauses:

$$
\begin{gathered}
\text { Sentence } 1:= \\
\text { (Clause } 1 \text { (SUB (CONJ pour que) } \\
\text { Sentence } 3) \text { ) }
\end{gathered}
$$

Sentence $3:$ Clause 2

3) for each clause, its main verb with its complementation:

Clause $1=$ ((SUBJECT HUM1) (VERB of frir) (OBJECT TOK 1) (A-OBJECT HUM2))

Clause $2=(($ SUBJECT HUM1) (VERB rendre) (OBJECT HUM2) (ATTRIBUTE heureuX))

A text template is turned into a text by the syntactic component. This component applles grammar rules (e.g. reduction of a subordinate clause to an infinitive form), synthesizes the tokens and performs the morphological routines. For these operations to be carried out, a text template includes, for each sentence, syntactic information that is represented in a tree whose nodes are syntactic categorles such as $\$$ (sentence), $C L$ (clause), SUBUECT or VERB. A text template may be made up of several sentences, however we will give an example with a single sentence because the operations of phonetic conversion and entering prosodic markers are performed within a sentence, independently of the other sentences. From the semantic representation (1), the text template may be:

\section{(2) ((S (CL (SUBJECT HUM1) (VERB of frir) (OBJECT TOK1) (A-OBJECT HUM2)) \\ (SUB (CONJ pour que) \\ ( $S$ (CL (SUBJECT HUMI) (VERB rendre) \\ (OBJECT HUM2) \\ (ATTRIBUTE heureux))))) .)}

The syntactic component turns it into a tree whose leaves are words:

\author{
((S (CL (SUBUECT (NP (N Jean))) \\ (VERB a offert) \\ (OBJECT (NP (DET des) (N anémones))) \\ (A-OBJECT (NP (PREP a) (NMarie)))) \\ (SUB (S (CL (CONJ pour) (PPV la) \\ (VERB rendre) \\ (ATTRIBUTE heureuse))))) .)
}

The erasing of the auxiliary vocabulary leads to:

\section{Wean a orfert des anemones a Marie pour la rendre heureuse.}

(John of fered anemones to Mary to make her happy.)

The syntactic component contains a morphological module (Courtois 1984) that works out an inflected form (e.g. heureuse, the feminine singular of heureux) given a basic form (e.g. heureux) and inflexional features (e.g. feminine, singular). This module is based on a dictionary that Indicates an inflexion mode for each bastc form. Each inflexion mode is assoclated with a rule that computes inflected forms.

The only modification made to the text generation system was to replace the morphological module with a morpho-phonetic module that proceeds to both inflexion and spelling-to-sound conversion. With this modification, the syntactic component produces a tree whose leaves are phonettc words.

\subsection{Inflesion and phonetic conversion}

A French morpho-phonetic system has been built to compute an inflected phonetic form given an orthographic basic word and inflextonal features (Laporte 1986). This system uses an intermediate phonological representation devised to optimize not only word inflexion and phonetic conversion but also llaison processing. The system works in the following way: given a basic orthographic form (e.g. heureux), its syntactic category and inflexional features (e.g. adjective, feminine, singular), a phonological dictionary works out its phonological representation (e.g. oroz). The word is then inflected (e.g. aroz') by means of a set of rules. These rules for phonological inflexion are much simpler than those that would be required for inflecting orthographic or phonetic words. By way of illustration, the feminine of the following adjectives; bon, grand, gros, leger, petit, oris, sot, vu can be obtained from their phonological representation with only I rule, whereas 3 would be required when starting from their orthographic representation and 8 from their phonet ic representation (Laporte 1984). The shift from phonological words to phonetic words entails knowing where llaisons should take place. Recall that a liaison takes place when both syntactic and phonological conditions are satisfied. In the semantic-representation-to-speech system, the syntactic tree of the sentence allows us to place liaison markers at the points where a liaison is syntactically allowed. The conversion of phonological words into phonetic words is then performed by a set of straightforward rules that check the phonological conditions of llaisons at the points where a liaison marker is present. Laporte's system is represented in Fig. 1.

From the text template (2), the syntactic component with the morpho-phonetic module outputs the following tree: 


\begin{tabular}{l|lcl|} 
& $\begin{array}{l}\text { Orthographical } \\
\text { representation }\end{array}$ & $\begin{array}{l}\text { Phonological } \\
\text { representation }\end{array}$ & $\begin{array}{l}\text { Phonetic } \\
\text { representation }\end{array}$ \\
\hline Basic words & $50,000 \longrightarrow 50,000$ & 50,000 \\
& \multicolumn{4}{|l|}{$\begin{array}{l}\text { dictionary } \\
\text { Inflected } \\
\text { words }\end{array}$} & 350,000 & $150,000 \stackrel{\text { rules }}{\longrightarrow} 150,000$ \\
\hline
\end{tabular}

Fig. 1 .

\section{(3) ((S (CL (SUBUECT (NP (N Ža))) \\ (VERB a ofER) \\ (OBJECT (NP (DET de) (N zanemon))) \\ (A-OBJECT (NP (PREP a) (N maRi))) \\ (SUB (S (CL (CONJ pUR) (PPV la) (VERB RădR) \\ (ATTRIBUTE gRøZ))))).)}

All the segmental phenomena have been taken into account and the next operation consists in entering prosodic markers in such a tree.

\subsection{The prosodic component 2}

Our prosodic system is based on syntax. However, there is not an isomorphic relation between the syntax and the prosody of a sentence. For example, the syntactic structures of Jean est parti a Paris (John went to Paris) and /l est parti a Paris (He went to Paris) are nearly identical, whereas there is a prosodic marker after the noun Jean and none after the pronoun if. Conversely, the syntactic representations of Jean a parle de ce probleme a Marie (John spoke about this problem to Mary) et Jean a parle de ce probleme a Paris (John spoke about this problem in Paris) are different although their prosodic markers are identical. As a consequence, we had to bulld a complete syntacticoprosodic grammar for French ${ }^{3}$. This grammar enables us to obtain a structure of a sentence that is isomorphic to its prosodic structure and computable from its syntactic structure. A syntactico-prosodic category corresponds

- elther to a syntactic category (e.g. the syntacticoprosodic category $S$ is equivalent to the syntactic category S),

- or to a sequence of syntactic categories (e.g. the prosodic category POV [post-verbal phrase] groups together all the complements which appear after the

2. This work was supported by CNET under contract no. $857 \mathrm{~B} 068$ with LADL.

3. This solution was also considered by Martin (1979). verbal syntagm [VS], and the prosodic category PRV [pre-verbal phrase] groups all the complements which appear before the VS),

- or to several syntactic categories (e.g. the prosodic category VC [verbal complement] corresponds to the following syntactic categorles: SUBJECT, OBJECT, A-OBJECT and ATTRIBUTE)

The first operation performed in the prosodic component thus consists in transforming the syntactic tree produced by the syntactic component into a syntactico-prosodic tree. From (3), this operation produces the following tree, in which the leaves are written in spelling representation for readability:
(4) $((S$ (CL (PRV (VC (NP (N Jean))))
(VS a of fert)
(POV (CV (NP (DET des) (N anémones))) (CV (NP (PREP a) (N Marie)))))
(SUB (S (CL (CONJ pour) (VS la rendre)
(VC heureuse)t))t).)

Besides the syntactico-prosodic grammar, a function SEG-C has been designed for each syntacticoprosodic category $C$. Such a function takes two arguments: a constituent $[X]$ of the category $C$ and the prosodic marker $x$ that is to appear to the right of $[X]$. It computes the prosodic markers that have to be entered in $[X]$. More precisely, if the syntactico-prosodic anaIysis of $[X]$ |s:

$$
[x]=\left(\left[x_{1}\right]\left[x_{2}\right] \ldots\left[x_{n}\right]\right)
$$

then:

$$
\text { (SEG-C }[X] x)=\left(\left[x_{1}\right] x_{1}\left[x_{2}\right] x_{2} \ldots\left[x_{n-1}\right] x_{n-1}\left[x_{n}\right] x\right)
$$
where $x_{1}, x_{2}, \ldots x_{n-1}$ are the appropriate markers. As an lllustration, the grammar lays down that

$$
[C L]=(\mathrm{CL}[\mathrm{CON}]|[\mathrm{PRV}]|[\mathrm{VS}][\mathrm{POV}] !)
$$

where the sign "l" following an element means that the element is either absent or present once. The function 
(SEG-CL $[\mathrm{Cl}] x$ ) indicates that

- when [PRV] is present, a marker $f(x)$ must be entered after it

- when [POV] is present, a marker $g(x)$ must be entered after [VS];

- In any case, $x$ is af ter the last constituent, l.e. [POV] when present, [VS] otherwise.

The algorithm for entering the markers works in a recursive manner by means of a function SEG. Given a constituent $[X]$ and the marker $x$ that is to appear to the right of $[X]$, this function figures out the category $C$ of $[X]$ and calls (SEG-C $[X] X$ ). Next, the functions

$$
\left(S E G-C_{1}\left[x_{1}\right] x_{1}\right), \quad\left(S E G-C_{2}\left[x_{2}\right] x_{2}\right), \ldots \quad\left(S E G-C_{n}\left[x_{n}\right] x\right)
$$

are called. For example, after (SEG-CL $[C L] x$ ) has been called, the entering of the markers into [PRV] when present is executed by

$$
(\text { SEG [PRV] } f(x))=(\text { SEG-PRV [PRV] } f(x))
$$

When [POV] is present, the functions (SEG [VS] $g(x)$ ) and (SEG [POV] $x$ ) are called, otherwise the function (SEG [VS] $x$ ) is called. The function SEG is first applied to the root of the arborescent syntactico-prosodic structure of the sentence involved and to its final punctuation mark ("." "," "?" "," ",") which corresponds to a prosodic marker. When the recursion is over, the auxlliary vocabulary is erased, leaving a phonetic chain with prosodic markers. As an example, the function SEG applied to (4) leads to the following result:

(5) Ža $[=]$ a ofer [\$] de zanemon [=] a maRi [,] puR la RådR [\$] @ROZ l.]

(Jean $[=]$ a offert [\$] des anémones [ $=$ ] à Marie [,] pour la rendre $[\$]$ heureuse $[$.$] )$

\section{Flgorithm and results}

The phonetic chain with prosodic markers produced by the system are forwarded to the speech synthesizer developed at CNET (Courbon \& Emerard 1982). The chart in Fig. 2 depicts the whole algorithm for generating spoken messages from semantic representations.

An implementation of the system has been developed in COMMON-LISP in the domain of terrorism crime newspaper reports. It produces phonetic chains with prosodic markers such as the ones shown below. Again, orthographic words replace phonetic symbols for readability. The syntactic conditioning of liaisons is
(3)

(1)

(2)


text template

syntactic component

with a morpho-phonetic module



syntactic tree

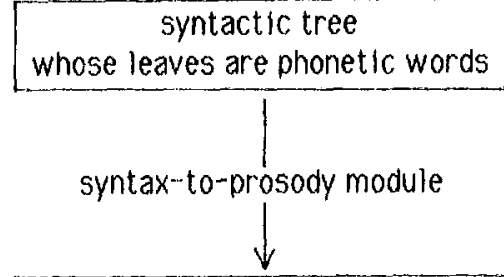

syntactico-prosodic tree

(4)

whose leaves are phonetic words

(5)

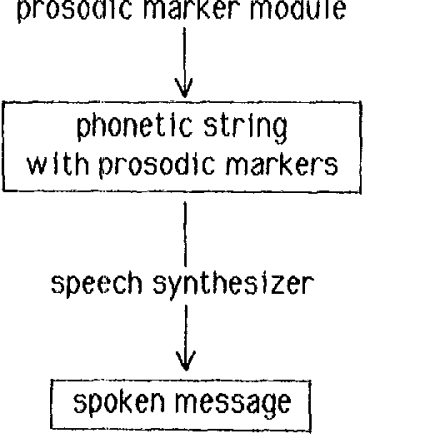

Fig. 2 
marked with the sign [-]. We present three syntactically different versions of the same terrorism crime to emphasize the robustness of the syntactic component and the entering of appropriate prosodic markers according to syntax.

Version 1. Indira Gandhi [\#] a eté assassinee [\$] mercredi a New-Dehli [.] Des [-] extremistes sikns [=] ont tire [@] sur [-] le oremier ministre indien [,] alors que $[-]$ elle [-] partait $[\$]$ de $[-]$ son domicile $[=]$ a pied $[*]$ pour se rendre $[\$]$ a $[-]$ son bureau $[$.]

(Indira Gandhi was assassinated Wednesday in NewDehll. Sikh extremists shot the Indian Prime Minister as she was leaving her home on foot to go to her of fice.)

Version 2. Des [-] extremistes sikns ["] ont assassine [@] Indira Gandhi [*] mercredi a New-Dehli [.] /Is [-] ont tire [@] sur [-] le premier ministre indien [,] alors que $[-]$ elle $[-]$ partait $[\$]$ de $[-]$ son domicile $[=]$ a pied $[*]$ pour se rendre [\$] aे [-] son bureau [.]

(Sikh extremists assassinated indira Gandhi Wednesday in New-Dehil. They shot the indian Prime Minister as she was leaving her home on foot to go to her office.)

Version 3. Mercredi a New-Dehli [,] des [-] extrémistes sikhs [=] ont assassine [@] Indira Gandhi [,] en tirant [@] sur [-] le premier ministre indien [*] alors que $[-]$ elle [-] partait [\$] de [-] son domicile $[=]$ a pied [*] pour se rendre $[\$]$ aे $[-]$ son bureau [.]

(Wednesday in New-Dehli, Sikh extremists assassinated Indira Gandhi by shooting the Indian Prime Minister as she was leaving her home on foot to go to her office.)

\section{Conclusion}

The semantic-representation-to-speech system developed in COMMON-LISP produces a spoken message of about 35 words in less than 1 second.

in our system, only the strategic component is domain dependent. The lexicon and discourse structures used to bulld the text templates are domain dependent inguistic data. The rest of the system is domain independent. Let us recapitulate the data and rules integrated in $\mathrm{It}$ :

- a syntactic component which can apply the French grammar rules whatever the structure of the texts and the syntax of the sentences;

- a complete phonological dictionary of the 50,000 basic forms of French and a set of rules for obtaining a phonetic text from a phonological text;
- a complete syntactico-prosodic grammar of French and a set of rules that enable us to enter prosodic markers in a sentence whatever the syntax of the sentence;

- a speech synthesizer and a synthesis software.

of course, these data and rules are only valld for French but it must be clear that the same kind of data is required for other languages and that the algorithm should be similar.

\section{Bibliogrophy}

COURBON, J. L., \& EMERARD, F., 1982, "SPARTE: A Textto-Speech Machine Using Synthesis by Diphones", IEEE Int. Conf. ASSP, pp. 1597-1600, Paris.

COURTOIS, B., 1984, "DELAS : Dictionnaire Electronique du LADL, mots Simples", Rapport technique du $L A D L$, $n^{9} \quad 12$

DANLOS, L., 1984 a, "Conceptual and Linguistic Decisions in Generation", in Proceedings or COLING 84, Stanford University, California.

DANLOS, L., 1984 b, "An Algorithm for Automatic Generation", in Proceedings or ECA/ 84, T. O'Shea éd., Elsevier Science Publishers BV, Amsterdam.

DANLOS L., 1986, The Linguistic Bases of Text Generation, Cambridge University Press, Cambridge.

EMERARD, F., 1977, synthesse par diohones et traitement de la prosodie, Thèse de troisième cycle, Université de Grenoble III.

LAPORTE, E., 1984, "Transductions et phonologle", DEA, Unlversité de Paris 7 .

LAPORTE, E., 1986, "Application de la morpho-phonologie * la production de textes phonétiques", Actes du seminaire "Lexiques et traitement automatique des langages", Toulouse.

MARTIN, Ph., 1979, "Un analyseur syntaxique pour la synthèse du texte", Actes des 100 journees d'études sur la parole, pp. 227-236, Grenoble.

SANTOS, J. M., \& NOMBELA, J. R, 1982, "Text-to-Speech Conversion in Spanish: A Complete Rule-Based Synthesis System", IEEE Int. Conr. ASSP, pp. 1593-1596, Paris. 